\title{
Selenium status and risk of prostate cancer in a Danish population
}

\author{
Malene Outzen ${ }^{1 *}$, Anne Tjønneland ${ }^{1}$, Erik H. Larsen ${ }^{2}$, Søren Friis ${ }^{3}$, Signe B. Larsen ${ }^{4}$, Jane Christensen ${ }^{3}$, \\ Kim Overvad ${ }^{5}$ and Anja Olsen ${ }^{1}$ \\ ${ }^{1}$ Diet, Genes, and Environment, Danish Cancer Society Research Center, Strandboulevarden 49, 2100 Copenhagen, Denmark \\ ${ }^{2}$ Division of Food Chemistry, National Food Institute, Technical University of Denmark, Mørkbøj Bygade 19, 2860 Søborg, Denmark \\ ${ }^{3}$ Statistics, Bioinformatics and Registry, Danish Cancer Society Research Center, Strandboulevarden 49, 2100 Copenhagen, Denmark \\ ${ }^{4}$ Survivorship, Danish Cancer Society Research Center, Strandboulevarden 49, 2100 Copenhagen, Denmark \\ ${ }^{5}$ Department of Public Health, Section for Epidemiology, Aarbus University, Bartholins Allé 2, 8000 Aarbus C, Denmark
}

(Submitted 28 September 2015 - Final revision received 27 January 2016 - Accepted 4 February 2016 - First published online 14 March 2016)

\section{Abstract}

Low-Se status may be associated with a higher risk of notably advanced prostate cancer. In a Danish population with a relatively low Se intake, we investigated the association between pre-diagnostic Se status and (1) the risk of total, advanced and high-grade prostate cancer and (2) all-cause and prostate cancer-specific mortality among men with prostate cancer. Within the Danish 'Diet, Cancer and Health' cohort, including 27179 men, we identified 784 cases with incident prostate cancer through 2007. Each case was risk set-matched to one control. Two-thirds ( $n$ 525) of the cases had advanced disease at the time of diagnosis, and among these 170 had high-grade disease; 305 cases died ( $n 212$ from prostate cancer) during follow-up through 2012. Plasma Se was not associated with total or advanced prostate cancer risk, but higher Se levels were associated with a lower risk of high-grade disease (HR 0.77; $95 \%$ CI 0.64, 0.94; $P=0.009$ ). In survival analyses, a higher level of plasma Se was associated with a lower risk of all-cause (HR 0.92; $95 \%$ CI 0.85, 1.00; $P=0.04$ ), but not prostate cancer-specific mortality. Higher levels of selenoprotein $\mathrm{P}$ were associated with a lower risk of high-grade disease (HR $0.85 ; 95 \%$ CI $0.74,0.97 ; P=0.01$ ), but not with the risk of or mortality from advanced prostate cancer. In conclusion, levels of plasma Se and selenoprotein $\mathrm{P}$ were not associated with the risk of total and advanced prostate cancer, but higher levels of these two biomarkers were associated with a lower risk of high-grade disease.

Key words: Selenium: Selenoprotein P: Prostate cancer: Prevention: Survival

Se, an essential trace mineral, has been suggested to possess cancer-protective effects ${ }^{(1)}$. The cancer-protective mechanisms of Se may be related to its incorporation in the amino acid selenocysteine in selenoproteins ${ }^{(2)}$, and they include reduction of DNA damage and oxidative stress, enhancement of immune response and induction of apoptosis ${ }^{(3-5)}$.

Dietary Se intake varies worldwide and is highly dependent on soil Se content ${ }^{(6)}$. The variation in human dietary intake is reflected in the global variation in blood Se levels ${ }^{(7)}$, with relatively low levels observed in Europe and higher levels in the $\mathrm{USA}^{(8,9)}$. These geographical differences in Se levels have been in focus in the discussion of Se and its relation to prostate cancer risk ${ }^{(10)}$. A recent report from the World Cancer Research Fund International concluded a 'limited-suggestive' relationship between 'low plasma Se concentrations' and higher risk of prostate cancer ${ }^{(11)}$. A systematic review and meta-analysis by Hurst et $a l^{(10)}$, published as a part of the update report by World Cancer Research Fund International, showed an inverse association between plasma/serum Se and especially advanced prostate cancer. On the basis of available results, which also included studies determining Se status by toenail Se concentrations, the authors also speculated that a U-shaped association might exist between Se levels and prostate cancer risk $^{(10)}$.

The evidence from randomised clinical trials is conflicting ${ }^{(1,10)}$. The Selenium and Vitamin E Cancer Prevention Trial found no effect of $200 \mu \mathrm{g}$ Se supplementation/d on incidence of prostate cancer in a high-Se US population (median baseline serum level approximately $136 \mathrm{ng} / \mathrm{ml})^{(12)}$. A post hoc analysis revealed, however, that Se supplementation increased the risk of high-grade prostate cancer in men with the highest baseline Se levels ${ }^{(13)}$. The smaller Nutritional Prevention of Cancer (NPC) trial also supplemented the participants with $200 \mu \mathrm{g} \mathrm{Se} / \mathrm{d}$, but it was conducted in a US population with lower baseline Se status (mean plasma Se approximately $115 \mathrm{ng} / \mathrm{ml})^{(14)}$. In this study, Se supplementation was related to decreased prostate cancer risk only in the subgroup of men with baseline Se levels $<123 \mathrm{ng} / \mathrm{ml}^{(15)}$.

Abbreviations: HR, hazard ratio; PSA, prostate-specific antigen.

* Corresponding author: M. Outzen, fax +453527 7731, email outzen@cancer.dk 
Results from the US Third National Health and Nutrition Examination Survey (NHANES III) are also compatible with a differential effect of Se supplementation on prostate cancer risk according to baseline Se status ${ }^{(16)}$. Study subjects in the NHANES III population had mean serum Se levels of $125 \mathrm{ng} / \mathrm{ml}$, and in this moderate Se level US population a non-linear association was suggested for all-cause and cancer mortality with higher risk at lower Se levels ${ }^{(16)}$.

Various biological markers of Se status have been considered for assessing Se exposure ${ }^{(17,18)}$. One biomarker is selenoprotein P, which is the major selenoprotein in plasma ${ }^{(19-21)}$. The primary role of this selenoprotein is to transport and deliver Se to tissues ${ }^{(19-21)}$. Selenoprotein $\mathrm{P}$ is expected to reach maximal concentration at plasma Se levels ranging from 90 to $125 \mathrm{ng} / \mathrm{ml}^{(22,23)}$, which is not reached in low-Se-status populations. Thus, selenoprotein $\mathrm{P}$ concentrations may be regarded as a measure of the functional Se status ${ }^{(17)}$. The association between selenoprotein $\mathrm{P}$ and prostate cancer risk has previously been studied in a low-Se-status population; however, they found no association ${ }^{(24)}$.

Overall, the results from observational studies and randomisedcontrolled trials suggest that there may be a narrow window of basic Se status associated with a lower risk of clinically advanced prostate cancer $^{(10)}$ and thus death from prostate cancer. An evaluation of this association will benefit from measurements of different biomarkers of Se, as they represent different biological aspects of Se status: short-term exposure (plasma Se) ${ }^{(25)}$ and functional Se status (selenoprotein P) ${ }^{(17)}$

Denmark represents a low-Se region with mean serum/plasma levels of Se approximately $90-100 \mathrm{ng} / \mathrm{ml}^{(26,27)}$, and consequently the Danish population is likely to have a suboptimal Se status. Thus, we hypothesised that low Se concentrations in blood among Danes are associated with a higher risk of prostate cancer, as well as higher prostate cancer-specific and all-cause mortality. In a case-control study nested within the Danish prospective 'Diet, Cancer and Health' cohort, we examined the association between pre-diagnostic blood Se, measured as plasma Se or selenoprotein $\mathrm{P}$, and risk of total, advanced and high-grade prostate cancer. Furthermore, we evaluated the association between pre-diagnostic Se levels and all-cause and prostate cancer-specific death among men diagnosed with prostate cancer.

\section{Methods}

\section{Study population}

This nested case-control study was conducted within the Danish population-based prospective cohort 'Diet, Cancer and Health'. Between December 1993 and May 1997, 80996 men aged 50-64 years and resident in the greater Copenhagen and Aarhus areas were selected from the Danish Central Population Registry and invited to participate in the cohort. All participants were born in Denmark and had no previous history of cancer. A total of 27179 men were enroled, corresponding to $34 \%$ of those invited. The cohort has been described in details previously ${ }^{(28)}$. The study protocol was approved by the regional ethics committees on human studies in Copenhagen and Aarhus and by the Danish Data Protection Agency. All participants provided written informed consent.

\section{Data collection}

At cohort enrolment, all participants completed a questionnaire on social and lifestyle factors. From this questionnaire, we obtained information about education (years of education after secondary school: low, medium, high), smoking status (never, former, current), smoking duration (years), current tobacco use $(\mathrm{g} / \mathrm{d})$ and participation in sport (yes/no).

At the study centre, a nonfasting 30-ml blood sample (collected in citrated and plain Venojects tubes) was taken from all participants, and plasma, serum, lymphocytes and erythrocytes were isolated. All samples were processed and frozen within $2 \mathrm{~h}$ at $-20^{\circ} \mathrm{C}$. Within the day of blood sampling, all samples were stored in liquid $\mathrm{N}_{2}$ vapour at a maximum of $-150^{\circ} \mathrm{C}$. Anthropometrical measurements such as weight and height were carried out by professional staff members; BMI was calculated as weight $(\mathrm{kg})$ divided by height squared $\left(\mathrm{m}^{2}\right)$.

\section{Ascertainment of diagnosis and mortality}

Information on vital status and emigration was obtained through linkage to the Central Population Registry using unique personal identification numbers. Information on cancer occurrence among cohort members was obtained through record linkage to the Danish Cancer Registry, which collects information on all cases of cancer diagnosed ${ }^{(29)}$. Each cohort member was followed up for prostate cancer occurrence from date of enrolment until the first date of diagnosis of any cancer (except for non-melanoma skin cancer), date of death or emigration or 31 December 2007, whichever came first. Loss to follow-up was a minor problem (0.02\%). We identified 911 cases of primary prostate cancer during the follow-up period (1993-2007). Of these, 127 were excluded because of lack of blood sample ( $n$ 40), failure in Se measurements ( $n$ 52), missing data on potential confounders ( $n 10)$ or implausible value $(n 1)$. Participants with missing information on selenoprotein $\mathrm{P}$ also had their plasma Se concentration excluded from the analyses to ensure that data were comparable, and finally incomplete case-control pairs were excluded ( $n$ 24), leaving 784 complete case-control pairs for the statistical analyses.

Each case of prostate cancer was matched 1:1 with a male control participant using a risk set sampling from eligible cohort members who were alive and free of cancer and had the same length of time from baseline to diagnosis. The matching criteria were age at blood collection ( \pm 6 months), time of day of blood collection $( \pm 1 \mathrm{~h})$ and fasting status (time since last meal: $<3,3-5,>5 \mathrm{~h}$ ). The half-life of Se in plasma is approximately $8 \mathrm{~h}^{(30)}$; matching by time of day and fasting status was done to minimise error by this factor.

By medical record review, we obtained information on stage and Gleason grade for the prostate cancer cases, as well as the underlying reason for diagnosis (urological symptoms, prostate-specific antigen (PSA) level at diagnosis or Gleason score at biopsy). Information on clinical TNM (tumour/nodes/ metastasis) stage was extracted from the Danish Cancer Registry, which holds information on TNM stage since 2004; for cases diagnosed before 2004, extent of disease was categorised as 'localised', 'regional' or 'distant'. We defined 'advanced 
prostate cancer' as $\geq \mathrm{T} 3$ or Gleason score $\geq 7$ or N1 or M1, or 'regional'/'distant' extent of disease or PSA $>15$. We defined 'high-grade prostate cancer' as Gleason score $\geq 8$.

Information on precise date of death and cause of death was obtained by linkage to the Danish Causes of Death Registry ${ }^{(31)}$. The case population of 784 men with a primary diagnosis of prostate cancer was followed up from date of diagnosis until the date of death or emigration or end of follow-up (31 December 2012). Of these, 305 died during follow-up, 212 of them from prostate cancer.

\section{Chemical analyses}

Se was determined by mixing $200 \mu \mathrm{l}$ of plasma with $5 \mathrm{ml}$ of an aqueous diluent containing $0 \cdot 5 \% \mathrm{v} / \mathrm{v}$ Triton X-100 (surfactant), $10 \% \mathrm{v} / \mathrm{v}$ ethanol and $1 \% \mathrm{v} / \mathrm{v}$ nitric acid. The Se concentration in the diluted plasma samples was determined by inductively coupled plasma MS (6100 ICP-DRC-MS; Perkin-Elmer-Sciex) for detection of $\mathrm{Se}$ as ${ }^{78} \mathrm{Se}$ against an external standard curve prepared in the same diluent. Diluted samples, standards and blanks were spiked at $10 \mathrm{ng} / \mathrm{ml}$ with ${ }^{93} \mathrm{Nb}$, which was used as an internal standard. On the basis of double determinations of $5 \%$ of all samples, the precision of the analyses was estimated at $2.0 \%$ (relative standard deviation; RSD), and the accuracy was assured by repeated analysis of the BCR 637 Human Serum certified reference material (CRM) (IRMM) throughout the entire analytical campaign. The mean value found was 84 (sD 3 ) ng Se/ml ( $n$ 85), which coincided with the certified value of 81 (SD 7) $\mathrm{ng} \mathrm{Se} / \mathrm{ml}$. The limit of detection (LOD) for Se in the undiluted plasma samples was $3 \mathrm{ng} \mathrm{Se} / \mathrm{ml}$.

The content of selenoprotein $\mathrm{P}$ in the selected subset of the plasma samples was determined as described in detail by Outzen et $a l .{ }^{(32)}$. In brief, the undiluted samples were injected onto a heparin-affinity HPLC column, which selectively retained selenoprotein P. Following an elution step with a solution of heparin at 500 units $/ \mathrm{ml}$, the selenoprotein was detected by ICP-DRC-MS as ${ }^{80}$ Se and quantified by post-column isotope dilution by adding a calibrant solution enriched in ${ }^{77} \mathrm{Se}$ via a T-piece. The ICP-MS was set to monitor the two Se isotopes. Precision of the analyses was estimated from double determinations of plasma samples ( $n$ 56) across the entire analytical campaign, and it was estimated at $2 \cdot 0 \%$ (RSD). The mean values for selenoprotein $\mathrm{P}$ quantified in the same CRM were 50 (sD 3$) \mathrm{ng} \mathrm{Se} / \mathrm{ml}(n$ 61) and amounted to $62 \%$ of all Se in the CRM. Because selenoprotein P has not been certified in this or any other CRM, evaluation of the analytical accuracy was not possible. The LOD for selenoprotein $\mathrm{P}$ was estimated at $6 \mathrm{ng} \mathrm{Se} / \mathrm{ml}$. All values of plasma Se and selenoprotein $\mathrm{P}$ were above the LOD.

PSA levels in serum were measured with the Architect PSA chemiluminescent microparticle immunoassay on the Architect i2000SR system (Abbott Diagnostics).

\section{Statistical analyses}

Associations between plasma Se and selenoprotein P and risk of prostate cancer were estimated by conditional logistic regression stratified by case-control pair. OR and 95\% CI were estimated from both crude (conditioned on the matching factors: age at blood collection, time of day of blood collection and fasting status) and multivariable models. Analyses were conducted for total prostate cancer (plasma Se) and separately for advanced and high-grade prostate cancer (plasma Se and selenoprotein $\mathrm{P}$ ).

The multivariable adjusted analyses included factors of potential relation to prostate cancer risk and/or blood Se levels, including BMI (continuous), education (low, medium, high), smoking status (never, former, current), smoking duration (continuous), smoking frequency (continuous) and participation in sport (yes/no). Effect measure modification by BMI and smoking was evaluated in the adjusted models for total and advanced prostate cancer using the likelihood ratio test statistics. These factors were considered to be involved in oxidative stress conditions and were therefore considered potential effect modifiers ${ }^{(33)}$.

In the adjusted analyses on prostate cancer risk (total and advanced prostate cancer), we evaluated whether the association differed by time from baseline to diagnosis ( $\leq 6$ and $>6$ years) or by PSA levels at baseline ( $\leq 4$ and $>4 \mathrm{ng} / \mathrm{ml}$ ). These sub-analyses were not performed for high-grade disease because of limited statistical power regarding this endpoint.

The associations between plasma Se and selenoprotein $\mathrm{P}$ and all-cause and prostate cancer-specific mortality among the prostate cancer cases were estimated by Cox proportional hazards models with follow-up (from date of diagnosis) as the underlying time-scale and stratification by age at diagnosis in 5-year intervals. Follow-up time was included as a time-dependent variable to account for minor violations of the proportional hazard assumption. From this model, hazard ratios (HR) and 95\% CI were estimated. The associations were estimated among all cases regardless of stage or grade of disease. The major part of prostate cancer-specific deaths occurred in cases with advanced disease. Associations were evaluated without and with adjustment for the above-mentioned potential confounders. Furthermore, potential effect modification on a multiplicative scale by BMI and smoking was evaluated.

The OR and HR for Se concentration were estimated as categorical (per quartile) and linear (per increment of concentration) variables. Quartile cut-off points were based on the distribution in controls (risk analyses) and prostate cancer cases (mortality analyses). The units used for estimation in the linear analyses corresponded approximately to the interquartile range of plasma Se (increment of $10 \mathrm{ng} / \mathrm{ml}$ ) and selenoprotein P (increment of $5 \mathrm{ng} \mathrm{Se} / \mathrm{ml}$ ) levels among control participants (risk analyses) and prostate cancer cases (mortality analyses). Before including these two Se variables into the models, the linearity of the association was evaluated graphically by linear splines with 3 knots placed at the quartile cut-off points for exposure distribution among cases ${ }^{(34)}$. Linearity of the quantitative variables included in the adjusted model (BMI, smoking duration, smoking frequency) was evaluated in the same way. None of the associations showed signs of deflection or threshold values.

Correlation between plasma Se and selenoprotein $\mathrm{P}$ was evaluated in the 525 controls using Pearson's correlations.

Two-sided $95 \%$ CI for the OR and HR were calculated. The procedure PHREG in the SAS software package (release 9.3; SAS Institute) was used for the statistical analyses. 


\section{Results}

Baseline characteristics of the total ( $n$ 784), advanced ( $n$ 525) and high-grade prostate cancer case groups $(n$ 170) and the control group ( $n$ 784) are shown in Table 1 . Cases had a longer education, whereas smoking habits, physical activity and plasma Se levels were similar among cases and controls. The median plasma Se concentrations were approximately $79 \mathrm{ng} / \mathrm{ml}$ in all four groups. The overall range of plasma Se of approximately $60-105 \mathrm{ng} / \mathrm{ml}$ confirmed the low-Se status of the entire population. The median concentration of selenoprotein $\mathrm{P}$ was approximately $50 \mathrm{ng} \mathrm{Se} / \mathrm{ml}$ in all groups.
The level of plasma Se was not associated with total or advanced prostate cancer risk (Table 2). Adjustment for potential confounders did not influence the OR estimates materially. Similarly, no substantial differences in OR were seen in analyses stratified by duration of follow-up ( $\leq 6 v$. $>6$ years) or by PSA levels at baseline $(\leq 4 \quad v .>4 \mathrm{ng} / \mathrm{ml})$. For high-grade disease, higher plasma Se levels were associated with a lower risk in both the minimally adjusted (HR 0.83; 95\% CI $0.71,0.98 ; P=0.03$ ) and in the confounder-adjusted model (HR 0.77; $95 \%$ CI 0.64, 0.94; $P=0.009$ ).

In the analyses of selenoprotein $\mathrm{P}$ among cases with advanced prostate cancer (Table 3), we observed no associations, irrespective of confounder control, duration of follow-up or baseline PSA levels.

Table 1. Characteristics of total, advanced and high-grade prostate cancer cases, and their matched controls (Medians and 5th-95th percentiles; numbers and percentages)

\begin{tabular}{|c|c|c|c|c|c|c|c|}
\hline & \multicolumn{7}{|c|}{ Case-control risk analysis } \\
\hline & Controls & \multicolumn{2}{|c|}{ Total cases } & \multicolumn{2}{|c|}{ Advanced cases } & \multicolumn{2}{|c|}{ High-grade cases } \\
\hline & $\%$ & $n$ & $\%$ & $n$ & $\%$ & $n$ & $\%$ \\
\hline$n$ & 784 & 784 & & 525 & & 170 & \\
\hline \multicolumn{8}{|l|}{ Age at baseline (years) } \\
\hline Median & 59 & \multicolumn{2}{|c|}{59} & \multicolumn{2}{|c|}{58} & \multicolumn{2}{|c|}{58} \\
\hline 5th-95th percentile & $51-64$ & \multicolumn{2}{|c|}{$51-64$} & \multicolumn{2}{|c|}{$51-64$} & \multicolumn{2}{|c|}{$51-64$} \\
\hline \multicolumn{8}{|l|}{ Age at diagnosis (years) } \\
\hline Median & - & \multicolumn{2}{|c|}{$66 \cdot 2$} & \multicolumn{2}{|c|}{$66 \cdot 5$} & \multicolumn{2}{|c|}{$67 \cdot 2$} \\
\hline 5th-95th percentile & - & \multicolumn{2}{|c|}{$58 \cdot 2-73 \cdot 9$} & \multicolumn{2}{|c|}{$58 \cdot 5-74 \cdot 2$} & & \\
\hline BMI $\left(\mathrm{kg} / \mathrm{m}^{2}\right)$ & & & & & & & \\
\hline Median & $26 \cdot 2$ & & & & & & \\
\hline 5th-95th percentile & $21 \cdot 6-33 \cdot 2$ & & 3.0 & & & & \\
\hline Education & & & & & & & \\
\hline Low school & $39 \cdot 7$ & 259 & $33 \cdot 1$ & 174 & $33 \cdot 1$ & 54 & 33.8 \\
\hline Medium school & 38.4 & 324 & $41 \cdot 3$ & 223 & $42 \cdot 5$ & 74 & 43.5 \\
\hline High school & 21.9 & 201 & $25 \cdot 6$ & 128 & $24 \cdot 4$ & 42 & 24.7 \\
\hline Smoking status at baseli & & & & & & & \\
\hline Never & $27 \cdot 9$ & 219 & $27 \cdot 9$ & 135 & $25 \cdot 7$ & 41 & $24 \cdot 1$ \\
\hline Former & $36 \cdot 9$ & 299 & $38 \cdot 2$ & 200 & $38 \cdot 1$ & 74 & 43.5 \\
\hline Current & $35 \cdot 2$ & 266 & 33.9 & 190 & $36 \cdot 2$ & 55 & $32 \cdot 3$ \\
\hline Smoking duration* (ye & & & & & & & \\
\hline Median & 33 & & & & & & \\
\hline 5th-95th percentile & $8-48$ & & & & & & \\
\hline Smoking frequency ${ }^{\star} \dagger$ & & & & & & & \\
\hline Median & 20 & & & & & & \\
\hline 5th-95th percentile & $5-40$ & & & & & & \\
\hline Participation in sport, at & & & & & & & \\
\hline Yes & $48 \cdot 1$ & 375 & $47 \cdot 8$ & 246 & $46 \cdot 9$ & 81 & $47 \cdot 6$ \\
\hline No & $51 \cdot 9$ & 409 & $52 \cdot 2$ & 279 & $53 \cdot 1$ & 89 & $52 \cdot 3$ \\
\hline Baseline plasma Se bion & & & & & & & \\
\hline $\mathrm{Se}(\mathrm{ng} / \mathrm{ml})$ & & & & & & & \\
\hline Median & $79 \cdot 1$ & & & & & & \\
\hline 5th-95th percentile & $61 \cdot 5-105 \cdot 5$ & 60. & $4 \cdot 0$ & & & & \\
\hline Selenoprotein $\mathrm{P}$ (ng $\mathrm{S}$ & & & & & & & \\
\hline Median & $50 \cdot 9 \ddagger$ & & & & & & \\
\hline 5th-95th percentile & $37 \cdot 3-71 \cdot 1$ & & & & & & \\
\hline Years between baselin & & & & & & & \\
\hline Median & - & & & & & & \\
\hline 5th-95th percentile & - & & & & & & \\
\hline Years between baseline & & & & & & & \\
\hline$\leq 6$ years & - & 212 & $27 \cdot 0$ & 141 & $26 \cdot 9$ & 31 & $18 \cdot 2$ \\
\hline$>6$ years & - & 572 & 73.0 & 384 & $73 \cdot 1$ & 139 & 80.8 \\
\hline PSA at baseline & & & & & & & \\
\hline$\leq 4 \mathrm{ng} / \mathrm{ml}$ & - & 421 & $53 \cdot 7$ & 245 & $46 \cdot 7$ & 91 & 53.5 \\
\hline$>4 \mathrm{ng} / \mathrm{ml}$ & - & 363 & $46 \cdot 3$ & 280 & $53 \cdot 3$ & 79 & 46.5 \\
\hline
\end{tabular}

PSA, prostate-specific antigen.

* Among current and former smokers.

† Among current smokers.

¥ Only measured in cases diagnosed with advanced prostate cancer disease and their matched controls, $n 525$. 
Table 2. Association between plasma selenium concentration and prostate cancer risk for total, advanced and high-grade prostate cancer (Odds ratios and $95 \%$ confidence intervals)

\begin{tabular}{|c|c|c|c|c|c|c|c|c|c|c|}
\hline & \multicolumn{7}{|c|}{ Quartiles of plasma Se* $(\mathrm{ng} / \mathrm{ml})$} & \multirow[b]{3}{*}{$P_{\text {trend }}$} & & \\
\hline & \multirow{2}{*}{$\frac{\leq 71.4}{\text { OR }}$} & \multicolumn{2}{|c|}{$>71.4 \leq 79.1$} & \multicolumn{2}{|c|}{$>79.1 \leq 88.9$} & \multicolumn{2}{|c|}{$>88.9$} & & \multicolumn{2}{|c|}{ Per $10 \mathrm{ng} / \mathrm{ml}$} \\
\hline & & OR & $95 \% \mathrm{Cl}$ & OR & $95 \% \mathrm{Cl}$ & OR & $95 \% \mathrm{Cl}$ & & OR & $95 \% \mathrm{Cl}$ \\
\hline \multicolumn{11}{|l|}{ Total prostate cancer } \\
\hline Cases/controls $(n)$ & $188 / 198$ & \multicolumn{2}{|c|}{$186 / 193$} & \multicolumn{2}{|c|}{$219 / 197$} & \multicolumn{2}{|c|}{$191 / 196$} & & \multicolumn{2}{|c|}{$784 / 784$} \\
\hline Unadjusted & 1.00 (Ref.) & 0.99 & $0.73,1.33$ & $1 \cdot 15$ & $0.86,1.52$ & 1.00 & $0.74,1.34$ & 0.71 & 1.01 & $0.95,1.09$ \\
\hline Adjusted $\dagger$ & 1.00 (Ref.) & 0.97 & $0.71,1.32$ & $1 \cdot 14$ & $0.86,1.53$ & 0.95 & $0.70,1.29$ & 0.88 & 1.01 & $0.94,1.08$ \\
\hline \multicolumn{11}{|l|}{ Case baseline PSA $†$} \\
\hline Cases/controls $(n)$ & $102 / 109$ & \multicolumn{2}{|c|}{$108 / 110$} & \multicolumn{2}{|c|}{$105 / 105$} & \multicolumn{2}{|c|}{$106 / 97$} & & \multicolumn{2}{|c|}{$421 / 421$} \\
\hline$\leq 4 \mathrm{ng} / \mathrm{ml}$ & 1.00 (Ref.) & 0.96 & $0.64,1.45$ & 0.98 & $0.65,1.49$ & 1.02 & $0.67,1.57$ & 0.84 & 1.01 & $0.91,1.12$ \\
\hline Cases/controls $(n)$ & $86 / 89$ & \multicolumn{2}{|c|}{$78 / 83$} & \multicolumn{2}{|c|}{$114 / 92$} & \multicolumn{2}{|c|}{$85 / 99$} & & \multicolumn{2}{|c|}{$363 / 363$} \\
\hline$>4 \mathrm{ng} / \mathrm{ml}$ & 1.00 (Ref.) & 0.97 & $0.60,1.58$ & 1.28 & $0.84,1.94$ & 0.88 & $0.56,1.37$ & 0.88 & 0.99 & $0.89,1.10$ \\
\hline \multicolumn{11}{|c|}{ Years between blood collection and diagnosis $†$} \\
\hline Cases/controls $(n)$ & $50 / 54$ & \multicolumn{2}{|c|}{$50 / 53$} & \multicolumn{2}{|c|}{$59 / 54$} & \multicolumn{2}{|c|}{$53 / 51$} & & \multicolumn{2}{|c|}{$212 / 212$} \\
\hline$\leq 6$ years & 1.00 (Ref.) & 1.13 & $0.60,2.13$ & 1.23 & $0.69,2 \cdot 17$ & 1.15 & $0.64,2.01$ & $0 \cdot 81$ & 1.02 & $0.89,1.17$ \\
\hline Cases/controls $(n)$ & $138 / 144$ & & $6 / 140$ & & $/ 143$ & & $3 / 145$ & & & 2/572 \\
\hline$>6$ years & 1.00 (Ref.) & 0.91 & $0.64,1.30$ & $1 \cdot 12$ & $0.79,1.57$ & 0.89 & $0.62,1.28$ & 0.97 & 1.00 & $0.92,1.09$ \\
\hline Advanced prostate canc & & & & & & & & & & \\
\hline Cases/controls $(n)$ & $137 / 130$ & & 9/129 & & /127 & & /139 & & & $5 / 525$ \\
\hline Unadjusted & 1.00 (Ref.) & 0.81 & $0.56,1.17$ & 1.05 & $0.74,1.49$ & 0.75 & $0.52,1.08$ & 0.34 & 0.96 & $0.88,1.05$ \\
\hline Adjusted $\dagger$ & 1.00 (Ref.) & 0.80 & $0.54,1.17$ & 1.07 & $0.75,1.54$ & 0.72 & $0.49,1.06$ & 0.34 & 0.96 & $0.87,1.05$ \\
\hline Case baseline PSAt & & & & & & & & & & \\
\hline Cases/controls $(n)$ & $67 / 62$ & & $1 / 66$ & & $3 / 57$ & & $/ 60$ & & & $5 / 245$ \\
\hline$\leq 4 \mathrm{ng} / \mathrm{ml}$ & 1.00 (Ref.) & 0.75 & $0.43,1.31$ & 0.80 & $0.44,1.46$ & 0.73 & $0.41,1.31$ & 0.56 & 0.96 & $0.83,1.11$ \\
\hline Cases/controls $(n)$ & $70 / 68$ & & $8 / 63$ & & $2 / 70$ & & $/ 79$ & & & $0 / 280$ \\
\hline$>4 \mathrm{ng} / \mathrm{ml}$ & 1.00 (Ref.) & 0.84 & $0.48,1.47$ & 1.25 & $0.78,2.01$ & 0.71 & $0.42,1.19$ & 0.36 & 0.94 & $0.83,1.07$ \\
\hline Years between blood & ection and dic & losist & & & & & & & & \\
\hline Cases/controls $(n)$ & $36 / 31$ & & 9/35 & & $1 / 37$ & & $5 / 38$ & & & $1 / 141$ \\
\hline$\leq 6$ years & 1.00 (Ref.) & 0.94 & $0.41,2 \cdot 14$ & $1 \cdot 13$ & $0.55,2.34$ & 0.95 & $0.44,2.04$ & 0.94 & 0.99 & $0.83,1.18$ \\
\hline Cases/controls $(n)$ & $101 / 99$ & & 0/94 & & 9/90 & & /101 & & & $4 / 384$ \\
\hline$>6$ years & 1.00 (Ref.) & 0.76 & $0.49,1 \cdot 19$ & 1.08 & $0.70,1.65$ & 0.65 & $0.41,1.04$ & 0.28 & 0.94 & $0.84,1.05$ \\
\hline High-grade prostate can & & & & & & & & & & \\
\hline Cases/controls $(n)$ & $48 / 38$ & & $3 / 40$ & & / $/ 47$ & & $3 / 45$ & & & 0/170 \\
\hline Unadjusted & 1.00 (Ref.) & 0.83 & $0.42,1.63$ & 0.77 & $0.43,1.41$ & 0.58 & $0.30,1.09$ & 0.03 & 0.83 & $0.71,0.98$ \\
\hline Adjusted $\dagger$ & 1.00 (Ref.) & 0.62 & $0.30,1.28$ & 0.62 & $0.32,1.22$ & 0.42 & $0.20,0.87$ & 0.009 & 0.77 & $0.64,0.94$ \\
\hline
\end{tabular}

Ref., referent values; PSA, prostate-specific antigen.

* Quartiles based on range among controls.

† Adjusted for BMI (continuous), education (low, medium, high), smoking status (never, former, current), smoking duration (continuous), smoking frequency (continuous), participation in sport (yes/no).

For high-grade disease, a lower risk was seen according to higher plasma selenoprotein $\mathrm{P}$ levels both in the minimally adjusted (HR 0.89; 95\% CI 0.79, 0.99; $P=0.04$ ) and the confounder-adjusted model (HR 0.85; 95\% CI 0.74, 0.97; $P=0 \cdot 01$ ).

Higher plasma Se levels were associated with lower all-cause mortality among prostate cancer patients. After adjustment for potential confounders, the association was still statistically significant, but attenuated (HR 0.92; $95 \%$ CI 0.85, 1.00; $P=0 \cdot 04$ ) (Table 4). Marginally, albeit not statistically significant, lower HR were found for prostate cancer-specific death with higher levels of plasma Se.

For selenoprotein P (Table 5), we found no significant reduction in mortality among men diagnosed with advanced prostate cancer with higher level, although the HR estimates were below unity. We did not find any apparent effect measure modification by BMI and smoking for either plasma Se or selenoprotein $\mathrm{P}$ in the risk and survival analysis (all $P>0.07$, results not shown).

Finally, we examined the correlation between levels of plasma Se and selenoprotein P. Fig 1 shows that the two measures were closely related (correlation coefficient of $0.79(P<0 \cdot 0001))$.

\section{Discussion}

In this cohort study, we found no associations between pre-diagnostic blood Se levels and risk of total or advanced prostate cancer in a study population with relatively low plasma Se levels $(60-105 \mathrm{ng} / \mathrm{ml})$. Stratification by follow-up time and PSA levels at baseline did not affect the associations. However, for high-grade prostate cancer, statistically significant lower risks were seen with higher plasma levels of both Se and selenoprotein P. Among prostate cancer patients, there seemed to be a slightly lower risk of overall death associated with higher pre-diagnostic plasma Se levels.

Loss to follow-up was a minimal problem (0.02\%) and selection bias was thus of little concern. The study was also devoid of recall bias, as the case-control study was nested within a prospective cohort study and Se levels were measured in pre-diagnostic blood samples. 
Table 3. Association between plasma selenoprotein $\mathrm{P}$ concentration and prostate cancer risk for advanced and high-grade prostate cancer (Odds ratios and $95 \%$ confidence intervals)

\begin{tabular}{|c|c|c|c|c|c|c|c|c|c|c|}
\hline & \multicolumn{7}{|c|}{ Quartiles of plasma selenoprotein $\mathrm{P}^{*}(\mathrm{ng} \mathrm{Se} / \mathrm{ml})$} & \multirow[b]{3}{*}{$P_{\text {trend }}$} & & \\
\hline & \multirow{2}{*}{$\frac{\leq 45 \cdot 1}{\text { OR }}$} & \multicolumn{2}{|c|}{$>45.1 \leq 50.9$} & \multicolumn{2}{|c|}{$>50.9 \leq 57.6$} & \multicolumn{2}{|c|}{$>57.6$} & & \multicolumn{2}{|c|}{ Per $5 \mathrm{ng} / \mathrm{ml}$} \\
\hline & & OR & $95 \% \mathrm{Cl}$ & OR & $95 \% \mathrm{Cl}$ & OR & $95 \% \mathrm{Cl}$ & & OR & $95 \% \mathrm{Cl}$ \\
\hline \multicolumn{11}{|l|}{ Advanced prostate cancer } \\
\hline Cases/controls $(n)$ & $135 / 131$ & \multicolumn{2}{|c|}{$129 / 132$} & \multicolumn{2}{|c|}{$146 / 130$} & \multicolumn{2}{|c|}{$115 / 132$} & & \multicolumn{2}{|c|}{$525 / 525$} \\
\hline Unadjusted & 1.0 (Ref.) & 0.92 & $0.65,1.31$ & 1.01 & $0.70,1.44$ & 0.78 & $0.53,1.14$ & 0.23 & 0.96 & $0.90,1.03$ \\
\hline Adjusted $†$ & 1.0 (Ref.) & 0.91 & $0.64,1.31$ & 1.01 & $0.70,1.47$ & 0.78 & $0.53,1.16$ & 0.20 & 0.96 & $0.89,1.02$ \\
\hline \multicolumn{11}{|l|}{ Case baseline PSA† } \\
\hline Cases/controls $(n)$ & $66 / 62$ & \multicolumn{2}{|r|}{$63 / 62$} & \multicolumn{2}{|c|}{$61 / 65$} & \multicolumn{2}{|c|}{$55 / 56$} & & \multicolumn{2}{|c|}{$245 / 245$} \\
\hline$\leq 4 \mathrm{ng} / \mathrm{ml}$ & 1.0 (Ref.) & 0.92 & $0.53,1.59$ & 0.80 & $0.45,1.41$ & 0.80 & $0.43,1.49$ & 0.28 & 0.94 & $0.85,1.05$ \\
\hline Cases/controls $(n)$ & $69 / 69$ & \multicolumn{2}{|r|}{$66 / 70$} & \multicolumn{2}{|c|}{$85 / 65$} & \multicolumn{2}{|c|}{$60 / 76$} & & \multicolumn{2}{|c|}{$280 / 280$} \\
\hline$>4 \mathrm{ng} / \mathrm{ml}$ & 1.0 (Ref.) & 0.93 & $0.58,1.51$ & 1.32 & $0.79,2.21$ & 0.75 & $0.44,1.27$ & 0.34 & 0.96 & $0.88,1.05$ \\
\hline \multicolumn{11}{|c|}{ Years between blood collection and diagnosis $\dagger$} \\
\hline Cases/controls $(n)$ & $38 / 34$ & \multicolumn{2}{|c|}{$31 / 36$} & \multicolumn{2}{|c|}{$39 / 32$} & \multicolumn{2}{|c|}{$33 / 39$} & & \multicolumn{2}{|c|}{$141 / 141$} \\
\hline$\leq 6$ years & 1.0 (Ref.) & 0.88 & $0.41,1.90$ & 1.28 & $0.60,2.71$ & 0.89 & $0.39,2.01$ & 0.98 & 1.00 & $0.88,1.14$ \\
\hline Cases/controls $(n)$ & $97 / 97$ & \multicolumn{2}{|r|}{$98 / 96$} & \multicolumn{2}{|c|}{$107 / 98$} & \multicolumn{2}{|c|}{$82 / 93$} & & \multicolumn{2}{|c|}{$384 / 384$} \\
\hline$>6$ years & 1.0 (Ref.) & 0.94 & $0.61,1.43$ & 0.98 & $0.63,1.53$ & 0.75 & $0.47,1.21$ & 0.17 & 0.94 & $0.87,1.03$ \\
\hline \multicolumn{11}{|c|}{ High-grade prostate cancer } \\
\hline Cases/controls $(n)$ & $46 / 37$ & \multicolumn{2}{|r|}{$47 / 37$} & \multicolumn{2}{|c|}{$45 / 50$} & & $2 / 46$ & & & /170 \\
\hline Unadjusted & 1.0 (Ref.) & 0.94 & $0.50,1.76$ & 0.67 & $0.37,1.23$ & 0.50 & $0.26,1.00$ & 0.04 & 0.89 & $0.79,0.99$ \\
\hline Adjusted $\dagger$ & 1.0 (Ref.) & 1.07 & $0.54,2.13$ & 0.53 & $0.27,1.05$ & 0.44 & $0.20,0.94$ & 0.01 & 0.85 & $0.74,0.97$ \\
\hline
\end{tabular}

Ref., referent values; PSA, prostate-specific antigen.

* Quartiles based on range among controls.

† Adjusted for BMI (continuous), education (low, medium, high), smoking status (never, former, current), smoking duration (continuous), smoking frequency (continuous), participation in sport (yes/no).

Table 4. Association between plasma selenium concentration and all-cause and prostate cancer-specific mortality among total prostate cancer cases (Hazard ratios (HR) and $95 \%$ confidence intervals)

\begin{tabular}{|c|c|c|c|c|c|c|c|c|c|c|}
\hline & \multicolumn{7}{|c|}{ Quartiles of plasma $\mathrm{Se}^{*}(\mathrm{ng} / \mathrm{ml})$} & \multirow[b]{3}{*}{$P_{\text {trend }}$} & & \\
\hline & \multirow{2}{*}{$\frac{\leq 71 \cdot 7}{\mathrm{HR}}$} & \multicolumn{2}{|c|}{$>71.7 \leq 79.9$} & \multicolumn{2}{|c|}{$>79.9 \leq 88.7$} & \multicolumn{2}{|c|}{$>88.7$} & & \multicolumn{2}{|c|}{ Per $10 \mathrm{ng} / \mathrm{ml}$} \\
\hline & & $\mathrm{HR}$ & $95 \% \mathrm{Cl}$ & $\mathrm{HR}$ & $95 \% \mathrm{Cl}$ & $\mathrm{HR}$ & $95 \% \mathrm{Cl}$ & & $\mathrm{HR}$ & $95 \% \mathrm{Cl}$ \\
\hline \multicolumn{11}{|c|}{ All-cause mortality } \\
\hline Events $(n)$ & 88 & \multicolumn{2}{|c|}{80} & \multicolumn{2}{|c|}{68} & \multicolumn{2}{|c|}{69} & & \multicolumn{2}{|c|}{305} \\
\hline Unadjusted & 1.0 (Ref.) & 1.01 & $0.74,1.37$ & 0.79 & $0.58,1.37$ & 0.76 & $0.55,1.04$ & 0.004 & 0.89 & $0.82,0.96$ \\
\hline Adjusted $\dagger$ & 1.0 (Ref.) & 1.06 & $0.77,1.44$ & 0.88 & $0.63,1.23$ & 0.88 & $0.62,1.25$ & 0.04 & 0.92 & $0.85,1.00$ \\
\hline \multicolumn{11}{|c|}{ Prostate cancer-specific mortality } \\
\hline Events $(n)$ & 56 & \multicolumn{2}{|c|}{55} & \multicolumn{2}{|c|}{53} & \multicolumn{2}{|c|}{48} & & \multicolumn{2}{|c|}{212} \\
\hline Unadjusted & 1.0 (Ref.) & 1.14 & $0.78,1.67$ & 1.01 & $0.68,1.50$ & 0.83 & $0.54,1.27$ & $0 \cdot 10$ & 0.93 & $0.84,1.01$ \\
\hline Adjusted $\dagger$ & 1.0 (Ref.) & 1.21 & $0.82,1.78$ & $1 \cdot 10$ & $0.73,1.63$ & 0.93 & $0.60,1.43$ & 0.22 & 0.94 & $0.86,1.04$ \\
\hline
\end{tabular}

Ref., referent values.

* Quartiles based on range among total cases diagnosed with prostate cancer.

† Adjusted for BMI (continuous), education (low, medium, high), smoking status (never, former, current), smoking duration (continuous), smoking frequency (continuous), participation in sport (yes/no).

We were able to adjust for a range of potential confounding factors, and the adjustment had only moderate influence on the associations. However, residual confounding from unmeasured or unknown factors associated with both Se levels and the study outcomes cannot be ruled out. The major limitation of our study relates to the fact that the assessment of Se concentrations originates from only a single blood sample. This may have introduced some exposure misclassification, although a single plasma Se measurement may be a valid estimate of long-term levels according to results from a study examining differences in two values over time (baseline and after 5 years) $(r \text { for correlation }=0.55, P=0.001)^{(35)}$. In the mortality analyses, we followed up each participant from his specific date of diagnosis until death or end of follow-up, and thus studied the association between pre-diagnostic Se levels and all-cause mortality among men diagnosed with prostate cancer. It cannot be excluded that pre-diagnostic Se levels are related to overall mortality in the entire cohort, and immortal time bias could, consequently, be an issue. Further, death related to low Se levels occurring before a later prostate cancer diagnosis cannot be excluded.

A recent meta-analysis reported a non-linear association between serum/plasma Se levels and risk of prostate cancer with a gradual decrease in risk with increasing levels in the range of 
Table 5. Association between plasma selenoprotein $\mathrm{P}$ concentration and all-cause and prostate cancer-specific mortality among cases diagnosed with advanced prostate cancer

(Hazard ratios (HR) and 95\% confidence intervals)

\begin{tabular}{|c|c|c|c|c|c|c|c|c|c|c|}
\hline & \multicolumn{7}{|c|}{ Quartiles of plasma selenoprotein $\mathrm{P}^{*}(\mathrm{Se} \mathrm{ng} / \mathrm{ml})$} & \multirow[b]{3}{*}{$P_{\text {trend }}$} & \multirow{2}{*}{\multicolumn{2}{|c|}{ Per $5 \mathrm{ng} / \mathrm{ml}$}} \\
\hline & \multirow{2}{*}{$\frac{\leq 44.7}{\mathrm{HR}}$} & \multicolumn{2}{|c|}{$>44.7 \leq 50.8$} & \multicolumn{2}{|c|}{$>50 \cdot 8 \leq 56 \cdot 3$} & \multicolumn{2}{|c|}{$>56 \cdot 3$} & & & \\
\hline & & $\mathrm{HR}$ & $95 \% \mathrm{Cl}$ & $\mathrm{HR}$ & $95 \% \mathrm{Cl}$ & $\mathrm{HR}$ & $95 \% \mathrm{Cl}$ & & $\mathrm{HR}$ & $95 \% \mathrm{Cl}$ \\
\hline \multicolumn{11}{|c|}{ All-cause mortality } \\
\hline Events $(n)$ & 70 & \multicolumn{2}{|r|}{63} & \multicolumn{2}{|c|}{69} & \multicolumn{2}{|c|}{60} & & \multicolumn{2}{|c|}{262} \\
\hline Unadjusted & 1.0 (Ref.) & 0.93 & $0.66,1.31$ & 1.07 & $0.76,1.49$ & 0.83 & $0.59,1.17$ & 0.21 & 0.96 & $0.90,1.02$ \\
\hline Adjusted $\dagger$ & 1.0 (Ref.) & 0.99 & $0.70,1.40$ & $1 \cdot 15$ & $0.82,1.62$ & 0.94 & $0.66,1.33$ & 0.60 & 0.98 & $0.92,1.05$ \\
\hline \multicolumn{11}{|c|}{ Prostate cancer-specific mortality } \\
\hline Events $(n)$ & 48 & \multicolumn{2}{|r|}{48} & \multicolumn{2}{|c|}{57} & \multicolumn{2}{|c|}{43} & & \multicolumn{2}{|c|}{196} \\
\hline Unadjusted & 1.0 (Ref.) & 1.02 & $0.68,1.53$ & 1.28 & $0.87,1.89$ & 0.86 & $0.57,1.30$ & 0.64 & 0.98 & $0.92,1.06$ \\
\hline Adjusted $\dagger$ & 1.0 (Ref.) & 1.05 & $0.69,1.58$ & 1.34 & $0.91,1.98$ & 0.92 & $0.61,1.40$ & 0.91 & 1.00 & $0.93,1.07$ \\
\hline
\end{tabular}

Ref., referent values.

* Quartiles based on range among cases diagnosed with advanced prostate cancer.

$\dagger$ Adjusted for BMI (continuous), education (low, medium, high), smoking status (never, former, current), smoking duration (continuous), smoking frequency (continuous), participation in sport (yes/no).

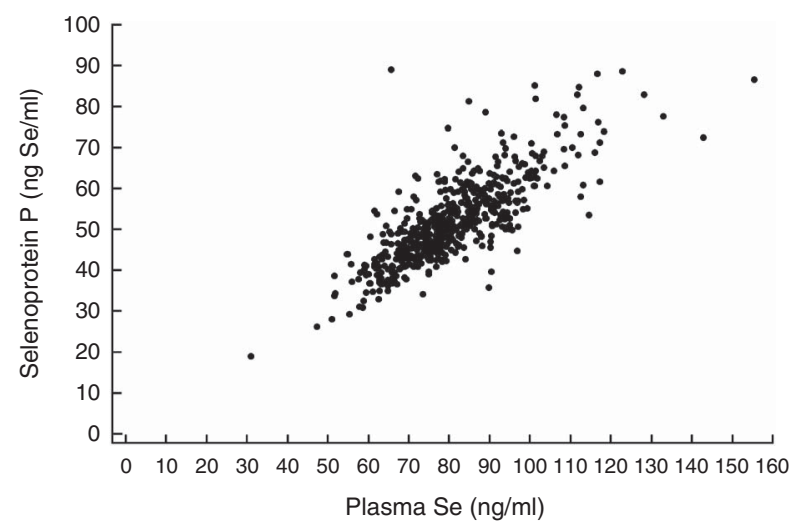

Fig. 1. Correlation between plasma selenoprotein $\mathrm{P}$ and plasma $\mathrm{Se}$ concentrations in 525 controls (Pearson's correlation, $r 0.79, P<0.0001$ ).

60-170 ng/ml (135 ng/ml: relative risk (RR) 0.85; $95 \%$ CI 0.74 , $0.97 ; 170 \mathrm{ng} / \mathrm{ml}:$ RR $0.75 ; 95 \%$ CI $0.65,0.86)^{(10)}$. For advanced prostate cancer, the meta-analysis indicated an even stronger association within this Se range ${ }^{(10)}$. Taking into account results from randomised supplementation trials indicating a reduced risk of prostate cancer related to Se supplementation among persons with low baseline levels ${ }^{(13,15)}$, we would expect low Se levels to be associated with an increased risk of prostate cancer in our low-exposure population. Although our results do not stand in contrast to the a priori hypothesis of an inverse association between increasing Se levels and prostate cancer risk in a low-Se population (all lower confidence limits $<1.00$ ), our findings of neutral to slightly reduced risk estimates for total and advanced prostate cancer do not provide strong support for the association. Our findings on total and advanced prostate cancer are very consistent with a previous prospective study conducted in the EPIC cohort (mean plasma level $71 \mathrm{ng} / \mathrm{ml}$ ), reporting an RR for prostate cancer close to unity in comparison of the highest $v$. lowest quintile of Se: RR 0.96; 95\% CI 0.70, 1.31 (36). Another prospective study in a European population with similar Se concentrations did, however, show a borderline significant association of slightly lower prostate cancer risk with higher serum Se levels (adjusted OR 0.89; 95\% CI $0.79,1.01)^{(24)}$. However, our finding of a significant lower risk for high-grade prostate cancer (Gleason score $\geq 8$ ) with higher pre-diagnostic plasma Se levels suggests that Se may have a role for the development of aggressive disease. We have not identified previous studies evaluating the Se-prostate cancer association for high-grade disease defined as a Gleason score $\geq 8$.

No previous studies evaluating survival among prostate cancer patients have been identified either. A few studies have reported on the association between Se levels and general mortality. A recent meta-analysis reported a marked lower mortality related to higher Se levels (OR 0.60; 95\% CI 0.39, $0.93)^{(37)}$. In the US NHANES III, a non-linear association was observed between Se status and all-cause and cancer mortality in 13887 participants with a mean serum Se level of approximately $125 \mathrm{ng} / \mathrm{ml}^{(16)}$. In that study, a reduced mortality was noted at serum Se levels up to $130 \mathrm{ng} / \mathrm{ml}^{(16)}$.

Plasma Se reflects recent Se exposure ${ }^{(25)}$, which could be a part of the explanation of the mainly null associations regarding total and advanced prostate cancer in the present study. Se content measured in toenail clippings are expected to be a marker of Se intake over a longer period, probably $6-12$ months ${ }^{(18,38)}$. Only few studies have, however, examined associations with prostate cancer for Se content in toenails ${ }^{(39-43)}$. Although not consistently, an overall picture of an inverse association originates from the toenail studies ${ }^{(39-42)}$. The strongest finding is reported from a Dutch prospective study. Here, a lower risk of advanced prostate cancer in comparison of the highest $v$. lowest quintile of toenail Se content (HR 0.37; 95\% CI 0.27, 0.51) was seen ${ }^{(39)}$. The plasma Se range in that study was estimated to be between 64 and $100 \mathrm{ng} /$ $\mathrm{ml}^{(39)}$, which is similar to the range in our study population. It is likely that the Se content measured in toenails is less affected by short-term fluctuations in Se levels, and this biomarker may, consequently, constitute a more relevant Se status biomarker.

Selenoprotein $\mathrm{P}$ is suggested to be the optimal marker of functional $\mathrm{Se}^{(17)}$, and the maximal concentration of selenoprotein $\mathrm{P}$ in humans is expected to be obtained at plasma Se levels ranging from 90 to $125 \mathrm{ng} / \mathrm{ml}^{(22,23)}$; only one fifth of our study subjects were in this range (approximately $1 \%$ had plasma Se 
levels $>125 \mathrm{ng} / \mathrm{ml}$ ). Therefore, we also included selenoprotein $\mathrm{P}$ as a biomarker of Se status. We did not find an association between selenoprotein $\mathrm{P}$ and advanced prostate cancer risk, which is in agreement with another study based on a European population $^{(24)}$. For high-grade disease, we did find a significant association of lower risk for higher selenoprotein $\mathrm{P}$ levels. The estimate was, though, in the same magnitude as seen for plasma Se and did not indicate that selenoprotein $\mathrm{P}$ is superior to plasma Se as Se biomarker.

Selenoprotein $\mathrm{P}$ has been found to be reduced in prostate tumours $^{(44)}$, and lower levels have also been observed in prostate cancer patients ${ }^{(45)}$. Because prostate cancers typically progress slowly and the disease has a long latency ${ }^{(46)}$, the levels of selenoprotein $\mathrm{P}$ and plasma Se might have been affected by the growing tumour already at baseline. We stratified the analyses according to time from baseline to diagnosis ( $\leq 6,>6$ years), but the associations were almost similar for the two follow-up periods. Stratifying the analyses according to time from baseline to diagnosis of 10 years gave similar results (results not shown). It is still possible, though, that the length of follow-up was too short to fully evaluate this hypothesis.

We also evaluated the association between Se levels and prostate cancer risk stratified by baseline PSA levels and found similar associations in the two groups $(\leq 4 v .>4 \mathrm{ng} / \mathrm{ml})$. We expected a stronger association for cases with PSA levels $>4 \mathrm{ng} / \mathrm{ml}$, because of the hypothesis that Se may have a role in delaying prostate cancer tumour progression. A previous prospective study reported a stronger association of Se and prostate cancer risk among men with higher baseline PSA levels ${ }^{(35)}$, and the NPC trial showed a reduced incidence of prostate cancer after Se supplementation among men with baseline PSA levels $\leq 4 \mathrm{ng} / \mathrm{ml}^{(15)}$.

The range of plasma Se in the present study population was, as expected, similar to what has been reported from other European populations (mean $70-80 \mathrm{ng} / \mathrm{ml})^{(36)}$, but lower than in studies conducted in US populations (median $105-140 \mathrm{ng} / \mathrm{ml})^{(10)}$. Furthermore, in our study population, we observed a strong correlation between plasma Se and selenoprotein $\mathrm{P}$, indicating that both Se measures are relevant to use as objective markers of Se exposure in a low-Se population. Our finding of a strong correlation is consistent with findings in other European populations in which correlations between 0.60 and 0.88 have been reported ${ }^{(24,47,48)}$.

Our study did not confirm higher blood Se or selenoprotein $\mathrm{P}$ levels to be associated with a reduced risk of total or advanced prostate cancer in a low-Se population. We did, however, find higher levels of both Se biomarkers to be associated with a lower risk of high-grade disease. Higher plasma Se levels were associated with a slightly reduced all-cause mortality among prostate cancer patients, whereas no association was found for prostate cancer-specific mortality.

\section{Acknowledgements}

The authors thank Data Managers Katja Boll and Nick Martinussen for assistance with data preparation, and Jytte Fogh Larsen for her administrative assistance.

This study was supported by funds from the Bjarne Saxhof Foundation and Danish Cancer Society. They had no role in the design, analysis or writing of this article.
M. O., E. H. L., K. O., A. T. and A. O. designed and conducted the research; E. H. L. was responsible for the laboratory analyses; S. B. L. was responsible for the medical record review; M. O. and J. C. analysed the data; M. O. wrote the paper under the supervision of A. O., K. O., S. F. and A. T.; M. O. and A. O. bear the primary responsibility for the content. All the authors critically reviewed the manuscript and approved the final manuscript.

The authors have no conflicts of interest to report.

\section{References}

1. Rayman MP (2012) Selenium and human health. Lancet 379, $1256-1268$

2. Hatfield DL, Tsuji PA, Carlson BA, et al. (2014) Selenium and selenocysteine: roles in cancer, health, and development. Trends Biochem Sci 39, 112-120.

3. Rayman MP (2005) Selenium in cancer prevention: a review of the evidence and mechanism of action. Proc Nutr Soc 64 , $527-542$

4. Nadiminty N \& Gao AC (2008) Mechanisms of selenium chemoprevention and therapy in prostate cancer. Mol Nutr Food Res 52, 1247-1260.

5. Fairweather-Tait SJ, Bao Y, Broadley MR, et al. (2011) Selenium in human health and disease. Antioxid Redox Signal 14, 1337-1383.

6. Combs GF Jr (2001) Selenium in global food systems. Br J Nutr 85, 517-547.

7. Rayman MP (2000) The importance of selenium to human health. Lancet 356, 233-241.

8. Brown KM \& Arthur JR (2001) Selenium, selenoproteins and human health: a review. Public Health Nutr 4, 593-599.

9. Rayman MP (2008) Food-chain selenium and human health: emphasis on intake. Br J Nutr 100, 254-268.

10. Hurst R, Hooper L, Norat T, et al. (2012) Selenium and prostate cancer: systematic review and meta-analysis. Am J Clin Nutr 96, 111-122.

11. World Cancer Research Fund International/American Institute for Cancer Research (WCRF/AICR) (2014) Continuous Update Project Report: Diet, Nutrition, Physical Activity, and Prostate Cancer. www.wcrf.org/sites/default/files/Prostate-Cancer2014-Report.pdf (accessed June 2015).

12. Lippman SM, Klein EA, Goodman PJ, et al. (2009) Effect of selenium and vitamin $\mathrm{E}$ on risk of prostate cancer and other cancers: the Selenium and Vitamin E Cancer Prevention Trial (SELECT). JAMA 301, 39-51.

13. Kristal AR, Darke AK, Morris JS, et al. (2014) Baseline selenium status and effects of selenium and vitamin e supplementation on prostate cancer risk. J Natl Cancer Inst 106, djt456.

14. Duffield-Lillico AJ, Reid ME, Turnbull BW, et al. (2002) Baseline characteristics and the effect of selenium supplementation on cancer incidence in a randomized clinical trial: a summary report of the nutritional prevention of cancer trial. Cancer Epidemiol Biomarkers Prev 11, 630-639.

15. Duffield-Lillico AJ, Dalkin BL, Reid ME, et al. (2003) Selenium supplementation, baseline plasma selenium status and incidence of prostate cancer: an analysis of the complete treatment period of the nutritional prevention of cancer trial. BJU Int 91, 608-612.

16. Bleys J, Navas-Acien A \& Guallar E (2008) Serum selenium levels and all-cause, cancer, and cardiovascular mortality among US adults. Arch Intern Med 168, 404-410.

17. Ashton K, Hooper L, Harvey LJ, et al. (2009) Methods of assessment of selenium status in humans: a systematic review. Am J Clin Nutr 89, 2025S-2039S. 
18. Longnecker MP, Stram DO, Taylor PR, et al. (1996) Use of selenium concentration in whole blood, serum, toenails, or urine as a surrogate measure of selenium intake. Epidemiology 7, 384-390.

19. Papp LV, Lu J, Holmgren A, et al. (2007) From selenium to selenoproteins: synthesis, identity, and their role in human health. Antioxid Redox Signal 9, 775-806.

20. Burk RF \& Hill KE (2005) Selenoprotein P: an extracellular protein with unique physical characteristics and a role in selenium homeostasis. Annu Rev Nutr 25, 215-235.

21. Rayman MP (2009) Selenoproteins and human health: insights from epidemiological data. Biochim Biophys Acta 1790, $1533-1540$.

22. Xia Y, Hill KE, Li P, et al. (2010) Optimization of selenoprotein P and other plasma selenium biomarkers for the assessment of the selenium nutritional requirement: a placebo-controlled, double-blind study of selenomethionine supplementation in selenium-deficient Chinese subjects. Am J Clin Nutr 92, 525-531.

23. Hurst R, Armah CN, Dainty JR, et al. (2010) Establishing optimal selenium status: results of a randomized, double-blind, placebo-controlled trial. Am J Clin Nutr 91, 923-931.

24. Steinbrecher A, Meplan C, Hesketh J, et al. (2010) Effects of selenium status and polymorphisms in selenoprotein genes on prostate cancer risk in a prospective study of European men. Cancer Epidemiol Biomarkers Prev 19, 2958-2968.

25. Van Dam RM \& Hunter D (2013) Biochemical indicators of dietary intake. In Nutritional Epidemiology, 3rd ed. pp. 150-212 [W Willett, editor]. New York, NY: Oxford University Press.

26. Ravn-Haren G, Krath BN, Overvad K, et al. (2008) Effect of long-term selenium yeast intervention on activity and gene expression of antioxidant and xenobiotic metabolising enzymes in healthy elderly volunteers from the Danish Prevention of Cancer by Intervention by Selenium (PRECISE) pilot study. Br J Nutr 99, 1190-1198.

27. Rasmussen LB, Hollenbach B, Laurberg P, et al. (2009) Serum selenium and selenoprotein $\mathrm{P}$ status in adult Danes-8-year followup. J Trace Elem Med Biol 23, 265-271.

28. Tjonneland A, Olsen A, Boll K, et al. (2007) Study design, exposure variables, and socioeconomic determinants of participation in Diet, Cancer and Health: a population-based prospective cohort study of 57,053 men and women in Denmark. Scand J Public Health 35, 432-441.

29. Storm HH, Michelsen EV, Clemmensen IH, et al. (1997) The Danish Cancer Registry - history, content, quality and use. Dan Med Bull 44, 535-539.

30. Bugel S, Larsen EH, Sloth JJ, et al. (2008) Absorption, excretion, and retention of selenium from a high selenium yeast in men with a high intake of selenium. Food Nutr Res 52, 10.3402/fnr. v52i0.1642.

31. Helweg-Larsen K (2011) The Danish register of causes of death. Scand J Public Health 39, 26-29.

32. Outzen M, Tjonneland A, Larsen EH, et al. (2015) The effect on selenium concentrations of a randomized intervention with fish and mussels in a population with relatively low habitual dietary selenium intake. Nutrients 7, 608-624.
33. Peters U \& Takata Y (2008) Selenium and the prevention of prostate and colorectal cancer. Mol Nutr Food Res 52, $1261-1272$

34. Greenland S (1995) Dose-response and trend analysis in epidemiology: alternatives to categorical analysis. Epidemiology 6, 356-365.

35. Li H, Stampfer MJ, Giovannucci EL, et al. (2004) A prospective study of plasma selenium levels and prostate cancer risk. J Natl Cancer Inst 96, 696-703.

36. Allen NE, Appleby PN, Roddam AW, et al. (2008) Plasma selenium concentration and prostate cancer risk: results from the European Prospective Investigation into Cancer and Nutrition (EPIC). Am J Clin Nutr 88, 1567-1575.

37. Vinceti M, Dennert G, Crespi CM, et al. (2014) Selenium for preventing cancer. Cochrane Database Syst Rev 3, CD005195.

38. Longnecker MP, Stampfer MJ, Morris JS, et al. (1993) A 1-y trial of the effect of high-selenium bread on selenium concentrations in blood and toenails. Am J Clin Nutr 57, 408-413.

39. Geybels MS, Verhage BA, van Schooten FJ, et al. (2013) Advanced prostate cancer risk in relation to toenail selenium levels. I Natl Cancer Inst 105, 1394-1401.

40. Yoshizawa K, Willett WC, Morris SJ, et al. (1998) Study of prediagnostic selenium level in toenails and the risk of advanced prostate cancer. I Natl Cancer Inst 90, 1219-1224.

41. Helzlsouer KJ, Huang HY, Alberg AJ, et al. (2000) Association between alpha-tocopherol, gamma-tocopherol, selenium, and subsequent prostate cancer. J Natl Cancer Inst 92, 2018-2023.

42. van den Brandt PA, Zeegers MP, Bode P, et al. (2003) Toenail selenium levels and the subsequent risk of prostate cancer: a prospective cohort study. Cancer Epidemiol Biomarkers Prev 12, 866-871

43. Ghadirian P, Maisonneuve P, Perret C, et al. (2000) A case-control study of toenail selenium and cancer of the breast, colon, and prostate. Cancer Detect Prev 24, 305-313.

44. Davis CD, Tsuji PA \& Milner JA (2012) Selenoproteins and cancer prevention. Annu Rev Nutr 32, 73-95.

45. Meyer HA, Hollenbach B, Stephan C, et al. (2009) Reduced serum selenoprotein $\mathrm{P}$ concentrations in German prostate cancer patients. Cancer Epidemiol Biomarkers Prev 18, 2386-2390.

46. Baade PD, Youlden DR \& Krnjacki LJ (2009) International epidemiology of prostate cancer: geographical distribution and secular trends. Mol Nutr Food Res 53, 171-184.

47. Hughes DJ, Fedirko V, Jenab M, et al. (2015) Selenium status is associated with colorectal cancer risk in the European prospective investigation of cancer and nutrition cohort. Int J Cancer 136, 1149-1161.

48. Hagmar L, Persson-Moschos M, Akesson B, et al. (1998) Plasma levels of selenium, selenoprotein $\mathrm{P}$ and glutathione peroxidase and their correlations to fish intake and serum levels of thyrotropin and thyroid hormones: a study on Latvian fish consumers. Eur J Clin Nutr 52, 796-800. 